\title{
Experimental Study on Diesel Particulate Filter Strategy for Generator
}

\author{
Jung-Hwang Choi ${ }^{1}$ and Doo-Sung Baik ${ }^{2 *}$ \\ ${ }^{1}$ Ph.D, Senior Research, CMC Tech, Korea \\ $2^{*}$ Professor, Mechanical Engineering, Daejin Univ., Korea \\ ${ }^{2}$ dsbaik@daejin.ac.kr
}

\begin{abstract}
Environmental substances emitted by diesel engines are fatal to humans. In particular, $P M_{2.5}$ penetrates deep into the lungs, providing the cause of lung cancer. Recently, the Euro 6 regulation is proposed and regulated to reduce the emission source emitted from automobiles, but due to the increasing number of vehicles, it is only suggested as a temporary measure. Not only the pollution sources emitted from automobiles, but also the increase of fine dust emitted from thermal power generation or fine dust introduced from outside by wind is very serious. In addition, the generation of fine dust in narrow spaces, for example subways, has a serious effect on human activities. Although research and development is conducted to collect such fine dust, it is not easy technology in reality. Currently, the fine dust collection technology is collected through the filter, but the collection performance depends on the pore size of the filter. The smaller the pore size, the higher the collection performance, but seriously affects the engine performance because the back pressure increases. Therefore, it is important to optimize the pore size, structure or material of the filter to minimize the influence on the back pressure. In addition, if the back pressure increases due to the filter, the engine performance is deteriorated, and a regeneration device that removes the collected PM is required. Such a filter regeneration device is an essential device especially for automobile engines. This paper aims to develop a technology to apply metal diesel particulate filter to a heavy-duty diesel engine for commercial generators to secure the optimization technology for occurred back-pressure satisfying emissions (PM, CO, HC) environmental regulations for regeneration strategy of diesel particulate filter in near future.
\end{abstract}

Keywords: DPF (Diesel Particulate Filter), Soot, Diesel, CO, HC, After-treatment device

\section{Introduction}

Atmospheric pollution problems such as global warming and photochemical smog are becoming more serious, and one of the main causes of air pollution is emissions from diesel engines. In order to solve the air pollution problem, the emission standards of exhaust gas are gradually strengthened. Industrial heavy-duty diesel engines emit tens of times more particulate matter than gasoline engines. Emissions account for more than $60 \%$ of the pollutants in large cities, and the Ministry of Environment is gradually tightening emission allowances for diesel engines to reduce emissions from soot [1][2][3]. As particulates contain fine and harmful chemicals, they cause diseases such as air quality deterioration, respiratory

Article history:

Received (January 2, 2020), Review Result (February 8, 2020), Accepted (March 13, 2020) 
disease and lung cancer. Therefore, environmental organizations have been developing catalysts and diesel particulate filter to reduce emissions [4][5][6]. In addition, a diesel engine with high thermal efficiency is being developed to reduce carbon dioxide emissions. However, diesel engines emit a lot of particulate matter (PM) and nitrogen oxides. In addition, since the characteristics of the exhaust gas have opposite characteristics, it is not easy to develop a technology that can simultaneously reduce the PM and nitrogen [6][7]. This is because a large amount of particulate matter is emitted at low combustion temperatures and nitrogen oxides are emitted at high temperatures depending on the combustion environment. The research on the reduction of exhaust gas of diesel engine includes the technology of reducing the exhaust gas during combustion (pre-treatment technology) and the post-treatment device which is mounted on the engine exhaust gas manifold to capture the exhaust gas already discharged from the engine [8] . Diesel engine after-treatment includes DOC (Diesel Oxidation Catalyst), Diesel Particulate Filter and Selective Catalytic Reduction to reduce HC, CO, SOF (Soluble Organic Fraction). In the DPF device, a wall-flow type ceramic honeycomb filter having a large surface area per unit volume and very high collection efficiency is mainly used. Common filter materials are monolithic Sic and Cordierite. However, due to the low durability of the material, research on DPFs with high mechanical strength and thermal conductivity of metals has begun. The key technologies for after-treatment in engines are filters, canning, catalytic, regeneration and combustion. As a technology for the posttreatment apparatus, Sic filters are being developed in Corning, USA, and Abiden, Japan. In particular, powder filters are being researched and developed mainly by HJS and Bosh. Other cartridge type filters have been developed and applied. The key is the filter, and important indicators of the performance of the after-treatment device are the filter pore size, heat resistance, thermal expansion resistance, thermal shock resistance, melting point and chemical durability. Generally applied Cordierite type has excellent collection efficiency but is weak to thermal shock and damages filter. And then, it tends to disturb the exhaust gas flow and cause an increase in back pressure. In addition, the material and configuration of the filter is directly related to the performance of the after-treatment device. Generally, the monolith type is used, and a cartridge or cross flow type is used in a diesel particulate filter as well. Cordierite is commonly used as a filter material, and there are also examples of application of silicon carbide and ceramic fiber as well metal fiber. In this study, the metal diesel particulate filter was applied the stationary industrial generators to secure the optimization technology for soot collection and regeneration strategy.

\section{Experiment}

\subsection{Experimental set up}

The experiment was carried out with 4 (four) $3000 \mathrm{KW}$ diesel engines for generators. Engine performance tests, soot and $\mathrm{HC}$ and $\mathrm{CO}$ emissions tests were performed with five engine loads $(0 \%, 25 \%, 50 \%, 75 \%$ and $100 \%)$. Fifteen DPFs were mounted in the engine exhaust manifold for the generator. In addition, the engine performance test according to the DPF installation was conducted on four generators. [Figure 1] shows the DPF mounted at the rear of the engine for the generator, and shows the controls and engine load regulators required for other engines and generator operation. Back pressure, soot, $\mathrm{CO}$ and $\mathrm{HC}$ were measured by using the measuring equipment for the $3000 \mathrm{KW}$ large generator. Equipment for back pressure measurement is shown in the [Figure. 2] of differential pressure gauge (Dwyer 447-3-FM). In measuring the back pressure, the pressure displayed on the control panel 
should be measured first and then the differential pressure is measured with a manometer. This is time consuming because the exhaust gas temperature is hot and the differential pressure pipe must be connected to the manometer to test until the generator and the diesel particulate filter device cool down. As a PM measuring instrument, a light transmission smoke measuring instrument (Op-160) was used as shown in [Figure 3]. As the PM measuring method was shown in [Figure. 4] and the PM was measured by drilling a drain hole at the outlet of the DPF. On the other hand, QR-401 instrument was used to measure CO and $\mathrm{HC}$ as shown in [Figure. 5].

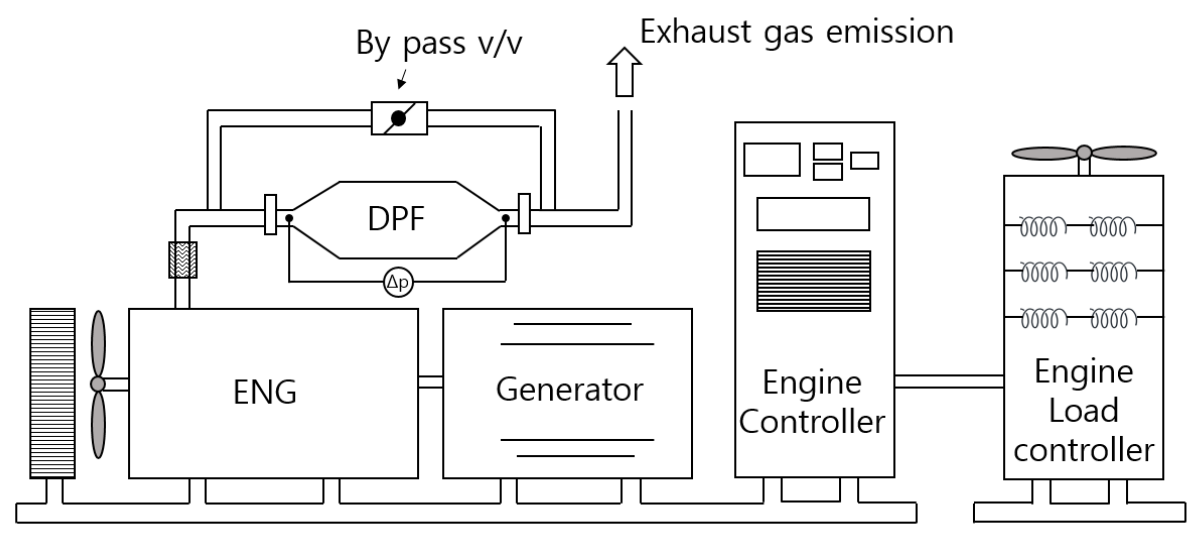

Figure 1. Schematic diagram for over-all emission reduction system

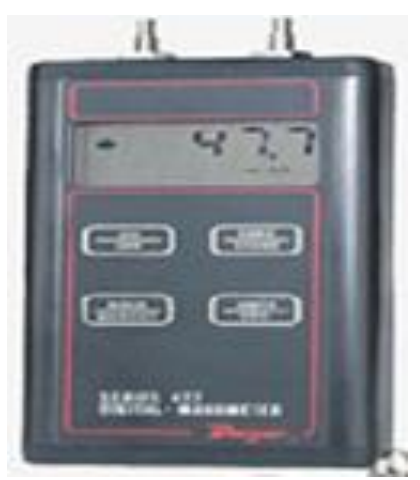

Figure 2. Different pressure gauge (Dwyer 447-3-FM)

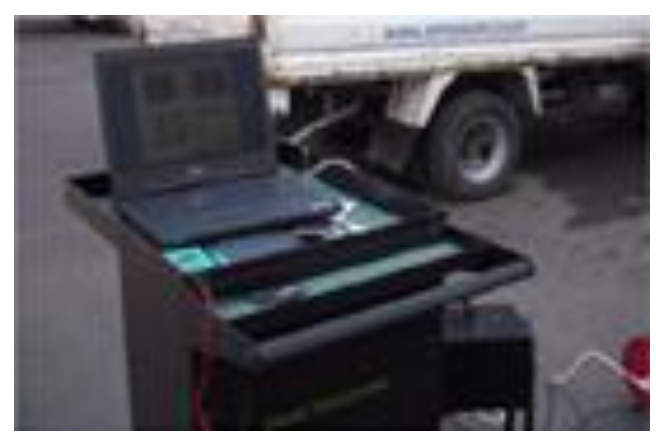

Figure 3. Smoke measuring instrument (Op-160) 


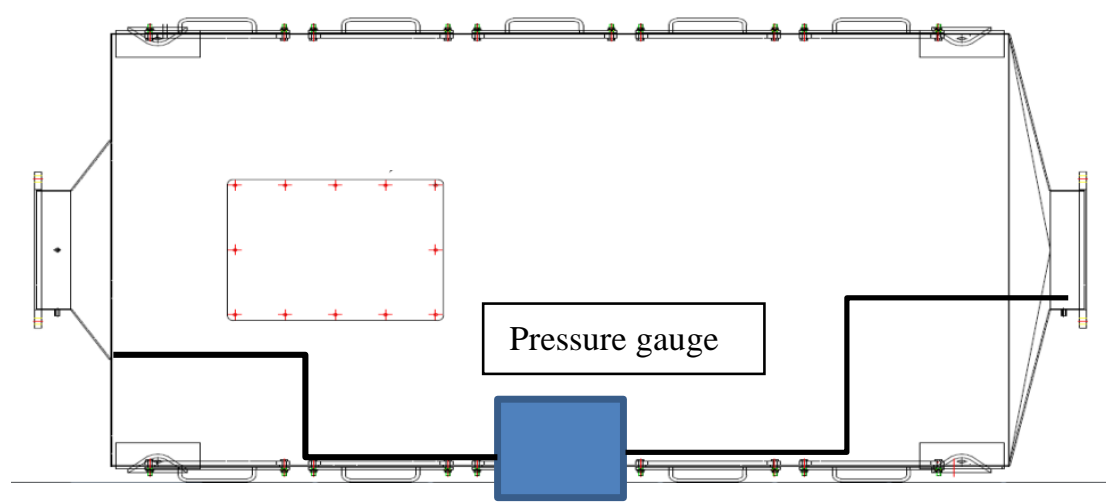

Figure 4. Pressure gauge for DPF

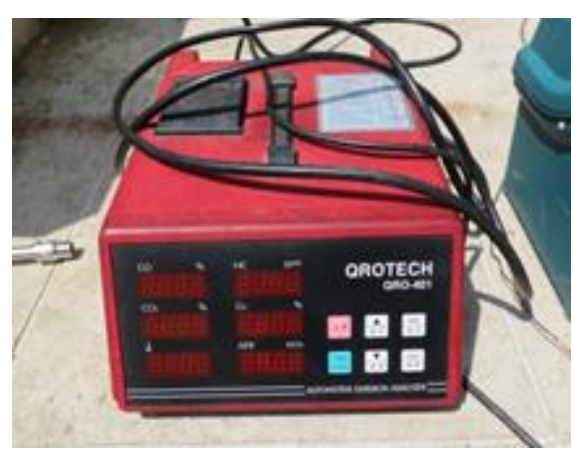

Figure 5. Gauge for $\mathrm{HC}$ and $\mathrm{CO}$ emission

\section{Experimental results}

\subsection{Engine performance test}

The test was carried out with soot reduction devices for four $4000 \mathrm{KW}$ generators. The test results were divided into $0,750,1500,2250$, and $3000 \mathrm{KW}$ according to the five load sections of $0 \%, 25 \%, 50 \%, 75 \%$ and $100 \%$. The power generation amount and exhaust gas temperature were shown as time passed [Figure 6]. [Figure 7] represents the amount of power generation and torque over time, and the experiment was measured to confirm the degradation of the generator performance due to the installation of diesel particulate filter. As shown in [Figure 7], the performance test was good overall and satisfied engine standard engine specification.

\subsection{Back pressure test}

The DPF was installed for four different $3000 \mathrm{KW}$ generators. Applied engine loads are $0 \%$, $25 \%, 50 \%, 75 \%$ and $100 \%$, and the corresponding engine powers were $0 \mathrm{KW}, 750 \mathrm{KW}$, $1500 \mathrm{KW}, 2250 \mathrm{KW}$ and $3000 \mathrm{KW}$. [Figure 8] represents that when the engine power increased with the engine load, the DPF showed increasing back pressure. When the engine power increased depending on the engine load, the back pressure increased due to the installed DPF. Back pressures at generators 1 to 4 at $25 \%(750 \mathrm{KW})$ of engine load were measured at 10, 12 , 10 and $14 \mathrm{MPa}$ and were below the standard back pressure of $15 \mathrm{MPa}$. In addition, at $50 \%$ of the engine load (1500 KW), the back pressures from generators 1 to 4 were 20, 26, 28, and 
$26 \mathrm{mbar}$ below the standard back pressure of $30 \mathrm{mbar}$. In addition, at $50 \%$ of the engine load $(1500 \mathrm{KW})$, the back pressures from generators 1 to 4 were 20,26, 28, and 26 mbar below the standard back pressure of 30 mbar. At $75 \%$ of the engine load $(2250 \mathrm{KW})$, back pressures from generators 1 to 4 were 34, 46, 36 and 44 mbar below the standard back pressure of 45 mbar. At $100 \%$ engine load $(3000 \mathrm{KW})$, back pressures from generators 1 to 4 were 46, 50, 48 and 53 mbar below the standard back pressure of $60 \%$ mbar.

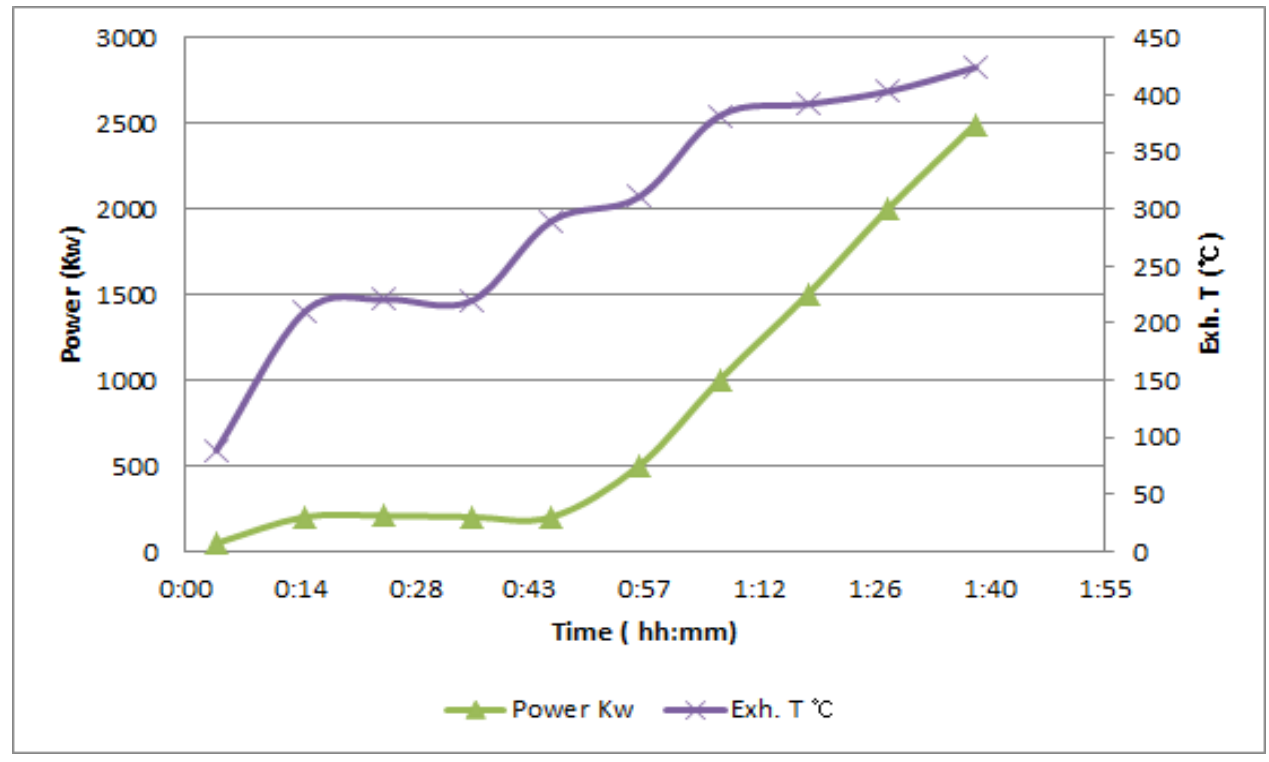

Figure 6. Power and exhaust gas temperature $(3000 \mathrm{KW})$

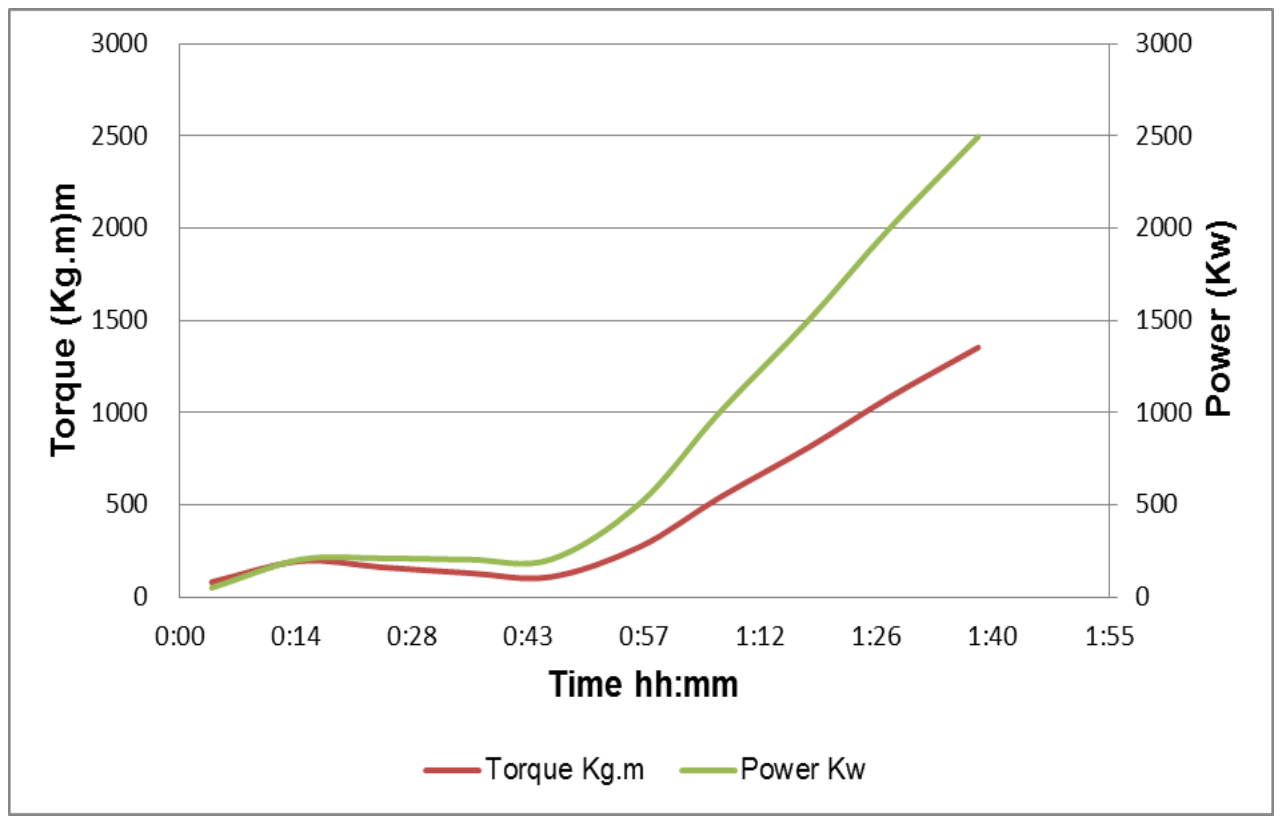

Figure 7. Power and torque (3000KW) 


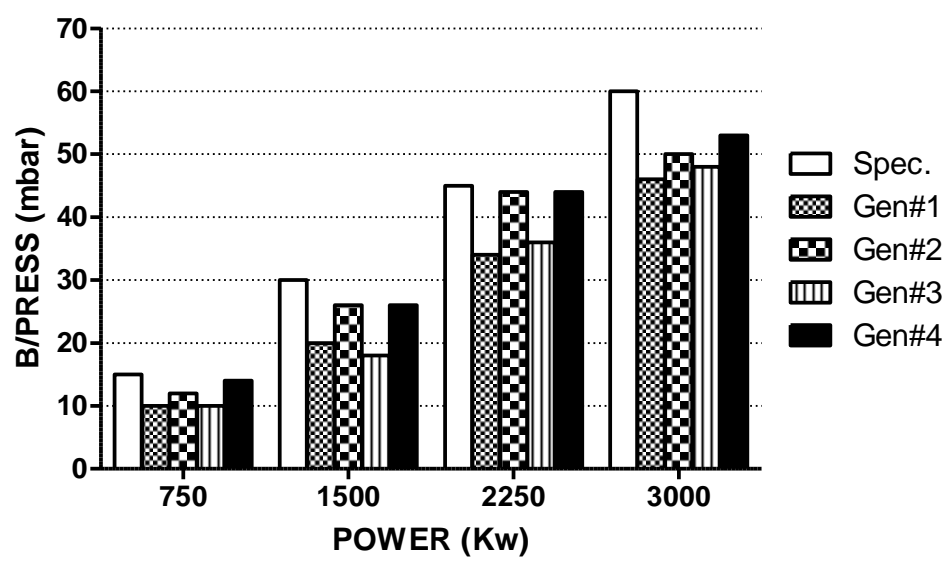

Figure 8. Back pressure

\subsection{Emission (PM, HC, CO) test}

[Figure 9] represents the soot (PM) generation by engine loads of $0 \%, 25 \%, 50 \%, 75 \%$ and $100 \%$ which are corresponding engine powers of $0 \mathrm{KW}, 750 \mathrm{KW}, 1500 \mathrm{KW}, 2250 \mathrm{KW}$ and $3000 \mathrm{KW}$. At $25 \%(750 \mathrm{KW})$ of engine load, PM concentrations at generators 1 through 4 were measured at $2.2 \%, 2.0 \%, 2.2 \%$ and $2.0 \%$ and were below the standard soot concentration of $10 \%$. At $50 \%(1500 \mathrm{KW})$ of engine load, the PMs from generators 1 to 4 were measured at less than $1.2 \%$ and were less than $10 \%$ below the standard specification. Similarly, at $75 \%(2250 \mathrm{KW})$ and $100 \%(3000 \mathrm{KW})$ engine loads, PM concentrations were lower than the standard concentration. Figure 10 indicates $\mathrm{CO}$ concentration by engine loads and $\mathrm{CO}$ concentration were very low compared to $\mathrm{CO}$ emission standard. [Figure 11] represents $\mathrm{HC}$ concentration by engine loads and $\mathrm{HC}$ concentration very lower compared to HC emission standard.

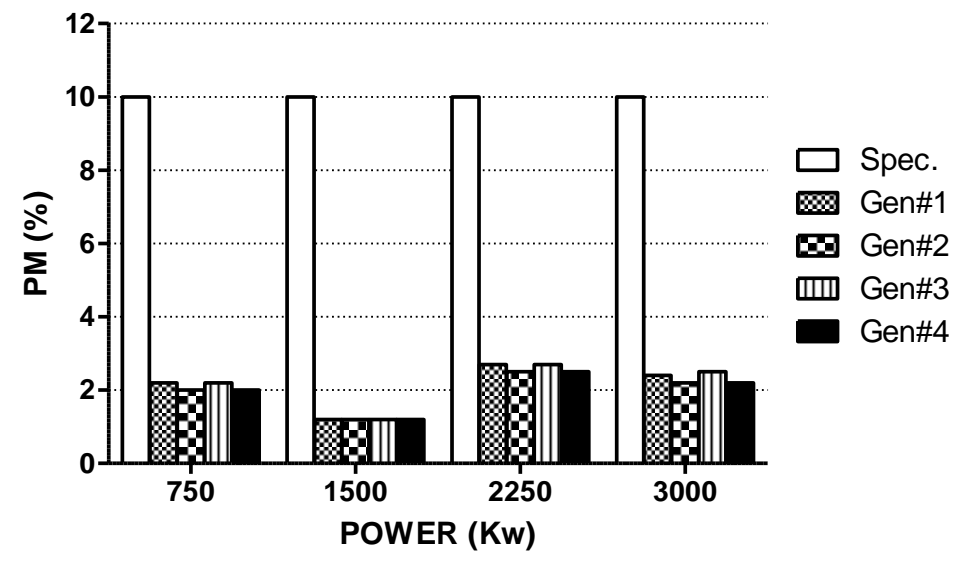

Figure 9. PM concentration

\section{Conclusions}

A number of metals DPFs were installed at the rear of four diesel engines for $3000 \mathrm{KW}$ generators to test whether they meet the exhaust gas emission standards. In order to lower the maximum allowable back pressure formed according to the arrangement of the DPFs, the 
DPF arrays were arranged in rows and columns (5X3). The allowable back pressure of the $3000 \mathrm{KW}$ large generator was $85 \mathrm{mbar}$ and the design back pressure is $60 \mathrm{mbar}$. It also shows a relatively stable back pressure at $100 \%$ engine load $(3000 \mathrm{KW})$ without increasing the back pressure. PM, HC and $\mathrm{CO}$ emissions satisfied the air environmental emission standard as well.

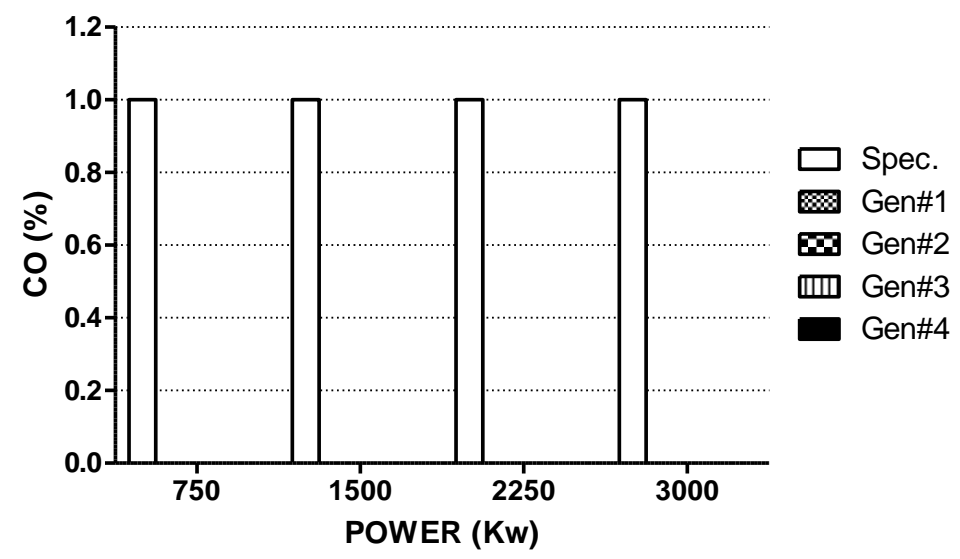

Figure 10. CO concentration

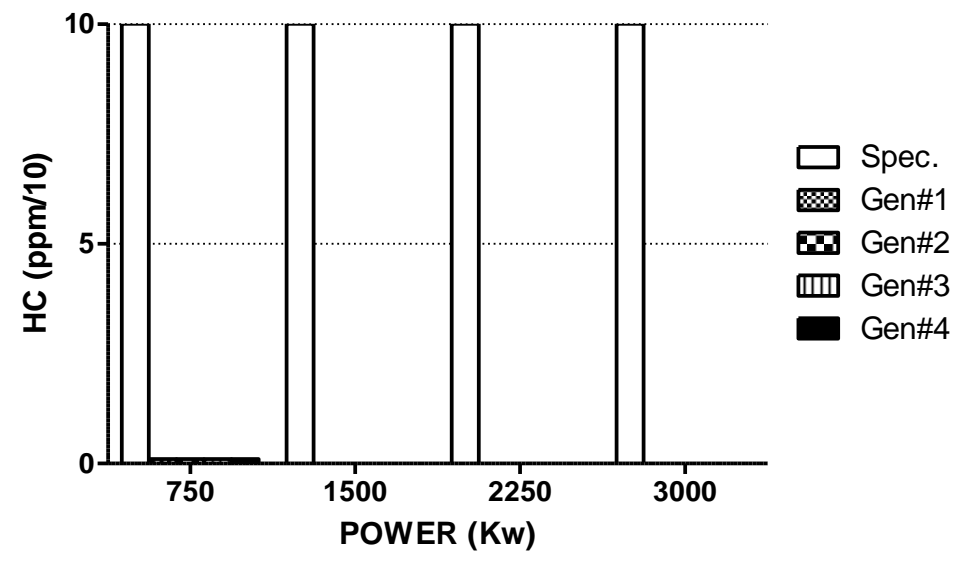

Figure 11. HC concentration

\section{References}

[1] S. Oh and B. Moon, "A study on prediction of flow characteristics and performance of a heavy-duty diesel engine with continuously regenerating method pm reduction," KSME, ISSN 1226-4881, vol.13, no.2, pp.51$58,(\mathbf{2 0 0 5})$

[2] T. Wittka, B. Holderbaum, T. Maunula, and Weissner, "Development and demonstration of LNT+SCR system for passenger car diesel applications,” SAE J. Engine, vol.7, no.3, pp.199-124, (2014)

[3] J. Park, B. West, M. Swartz, and S. Huff, "Characterization of lean NOx trap catalysts with in-cylinder regeneration strategies," SAE 2008-01-0448, (2008)

[4] J. D. Huang and R. J., "Crookes, assessment of simulated biogas as a fuel for the spark-ignition engine," Fuel, vol.77, pp.1793-1801, (1998)

[5] E. Porpatham, A. Ramesh, and B. Nagalingam, "Investigation on the effect of concentration of methane in biogas when used as a fuel for a spark ignition engine," Fuel 87, pp.1651-1659, (2008) DOI: 10.1016/j.fuel.2007.08.014. 
[6] P. G Tewari, J. P. Subrahmanyam, and M. K., Gajendrababu, "Experimental investigations on the performance characteristics of a producer gas fueled spark ignition engine," SAE paper 2001-01-1189 (2001)

[7] A. K. Agarwal and L. M. Das, "Biodiesel development and characterization for use as a fuel in compression ignition engines," Transactions of ASME, vol.123, pp.440-447, (2001)

[8] J. Choi and D. Baik, "A study on the development of smoke reduction device for large scale generators, Asiapacific society of convergent research interchange," 1st Domestic and International Integration Conference, ISSN 979-11-966392-4-2, pp.43, (2020) 